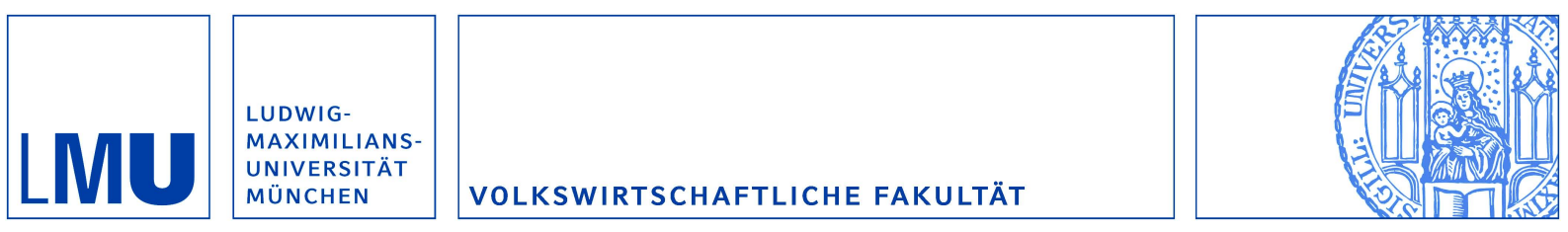

Börner, Kira und Hainz, Christa:

The Political Economy of Corruption and the Role of Financial Institutions

Munich Discussion Paper No. 2004-19

Department of Economics

University of Munich

Volkswirtschaftliche Fakultät

Ludwig-Maximilians-Universität München

Online at https://doi.org/10.5282/ubm/epub.411 


\title{
The Political Economy of Corruption and the Role of Financial Institutions*
}

\author{
Kira Börner \\ University of Munich ${ }^{\dagger}$
}

\author{
Christa Hainz \\ University of Munich and CESifo $\ddagger$
}

August 18, 2004

\begin{abstract}
In transition and developing countries, we observe rather high levels of corruption even if they have democratic political systems. This is surprising from a political economy perspective, as the majority of people generally suffers from high corruption levels. Our model is based on the fact that corrupt officials have to pay an entry fee to get lucrative positions. In a probabilistic voting model, we show that a lack of financial institutions can lead to more corruption as more voters become part of the corrupt system. Well-functioning financial institutions, in turn, can increase the political support for anti-corruption measures.
\end{abstract}

JEL-Classification: D73, D72, O17

Keywords: Corruption, Financial Markets, Institutions, Development, Voting

\footnotetext{
${ }^{*}$ The authors would like to thank Ulrich Berger, Monika Schnitzer, seminar participants at the University of Munich and at the SHEE/SITE Workshop on Transition and Institutional Analysis, Stockholm, as well as participants of the CESifo Area Conference on Public Sector Economics 2004, for helpful comments and suggestions. The usual disclaimer applies. Financial support by FOROST is gratefully acknowledged.

${ }^{\dagger}$ Department of Economics, University of Munich, Akademiestr. 1/III, 80799 Munich, Tel.: 49-89-2180 2766, Fax.: 49-89-2180 2767, email: kira.boerner@lrz.uni-muenchen.de

${ }^{\ddagger}$ Department of Economics, University of Munich, Akademiestr. 1/III, 80799 Munich, Tel.: 49-89-2180 3232, Fax.: 49-89-2180 2767, e-mail: christa.hainz@lrz.uni-muenchen.de.
} 


\section{Introduction}

In transition countries and developing countries, we observe rather high levels of corruption even if these countries have democratic systems. This is particularly surprising from a political economy perspective, as the majority of people generally suffers under a high level of corruption. In these countries, corruption spreads over all levels of the bureaucracy. Not only the officials dealing with firms and households demand bribes for providing particular services. Also the upper level bureaucrats want to benefit from these revenues from corruption. Therefore, they demand an entry fee for the lucrative positions in the bureaucracy. The corrupt officials and the superiors are the groups in the population that benefit from corruption. However, their share of the population is too small to explain the persistence of corruption in democratic regimes.

Investigating how corruption spreads through the different levels of the bureaucracy helps to explain its persistence. How does the mode of financing the entry fee influence the political support for anti-corruption campaigns? Does a functioning financial market change the way in which the entry fee is financed? So far, the literature does not provide answers to these questions. In a probabilistic voting model, we study how the existence of a financial market changes the political support for anti-corruption measures and alters thus the corruption level that is chosen in the political process. In our model, the corrupt officials have to pay entry fees to their superiors. Since the entry fee cannot be financed by the officials' savings, they have to borrow at least a part of the amount. ${ }^{1}$ If financial markets are absent, they may resort to their relatives or friends. Since the relatives' return depends on the level of corruption, these financial transactions give them a stake in corruption. Thereby, they might not have the incentive to support anti-corruption campaigns. As a consequence, the level of corruption that is sustained in the political process is higher.

If financial markets are functioning, the influence of banks depends on their possibilities to screen: When banks possess a perfect screening technology that allows them to deny credit to those debtors who use the money for financing an entry fee, the corrupt officials will still borrow from their relatives. However, compared to the case without financial institutions, the interest of corrupt officials and relatives in corruption decreases: The relatives have the opportunity to save at the bank. This new outside option reduces the net surplus from corruption for corrupt officials and relatives. This increases the corrupt officials' and the relatives' support for anti-corruption campaigns. When banks are not able to screen and grant credits also to corrupt officials, the corrupt officials finance the entry fee by taking a bank credit. Although the corrupt officials would prefer to borrow from their relatives in order to give them an interest in corruption, they cannot coordinate to do so. Therefore, the relatives do not have a stake in corruption and become supporters of anti-corruption policies. Lower corruption in the presence of a functioning financial system then is the result of a coordination failure among the corrupt officials.

Our paper is related to two different strands of literature. The first is the literature about the effects of institutions on economic activity: La Porta, Lopez-de-Silanes, Shleifer and Vishny

\footnotetext{
${ }^{1}$ For example, engineers of the water irrigation system in India pay up to 14 times their annual salary. See Wade (1982) p. 305, and the discussion in section 2.
} 
(LLSV) show in a series of papers how legal institutions affect the evolution of features of the economic system such as the financing decisions of firms or corporate governance (LLSV 1997, 1998, 2000). Persson, Tabellini, and Trebbi (2003) empirically examine the direct relationship between political institutions and corruption. They find that proportional electoral systems are likely to have higher corruption levels. We take the causality one step further by arguing that financial institutions shape the political preferences of the constituents by offering them a broader set of financing opportunities. By this channel, financial institutions have a positive impact on the political support for anti-corruption measures. This, in turn, makes political and legal institutions more effective in constraining corruption.

Second, there is a large body of literature on the causes and consequences of corruption, both empirical and theoretical. ${ }^{2}$ Initially, the theoretical literature on corruption emphasized the positive effect of the officials' opportunistic behavior on allocative efficiency. ${ }^{3}$ In contrast to that, the results of the empirical studies clearly demonstrate the negative impact of corruption on investment and, consequently, on growth (Mauro, 1995; Knack and Keefer, 1996). One explanation for the negative impact of corruption on investment is given by Foellmi and Oechslin (2003). They argue that firms receive credit only if they can offer sufficient collateral. However, firms have to pay bribes to start a business. This reduces the available collateral. Thus, firms with an intermediate wealth are driven out of the credit market.

Concerning the causes, Abed and Davoodi (2000) show that, at least for transition countries, structural reforms are more important than corruption in explaining a country's macroeconomic performance. However, the lack of structural and institutional reforms may give rise to more corruption. Treisman (2000) finds in his empirical study that the current level of democracy in a country does not significantly influence the level of corruption. His analysis of "perceived corruption" shows that more developed economies and and those countries with a longer exposure to democracy are less corrupt. ${ }^{4}$ Our result that the support for anti-corruption campaigns in a democratic country depends on the effectiveness of financial institutions is in line with these results as countries with a longer democratic tradition will also have developed better institutions.

\footnotetext{
${ }^{2}$ For surveys on corruption see Aidt (2003), Bardhan (1997) and Jain (2001a). For edited volumes on corruption, see Jain (2001b), and Jain (1998).

${ }^{3}$ However, these arguments are based on a second-best reasoning: Given that the allocation mechanisms of the government do not function, corruption can in some cases improve efficiency. In Lui (1985), the government demands a uniform price for the public good because it cannot price-discriminate. In a so-called "queue model", the corrupt official minimizes the average time costs of waiting. He first serves those customers who are willing to pay higher bribes. Beck and Maher (1986) point to similarities in outcomes of auctions and to allocation mechanism based on bribes. For a discussion of these arguments and an analysis of the costs of corruption, see Rose-Ackerman (1999).

${ }^{4}$ Treisman's analysis is based on survey responses of businessmen and local residents. A justification for such subjective measures of corruption is that the perception of corruption influences the political and economic behavior of citizens, e.g., voting or investment decisions (Treisman, 2000, p. 400).
} 
In the theoretical literature, the predominant cause for corruption on lower levels of the bureaucracy is seen in the principal-agent relationship between bureaucrats and their superiors. Generally, in this literature, the different levels of the bureaucracy on which corruption occurs are studied separately. One exception is Hillman and Katz (1987): They show that rent seeking can provoke contests for the positions that entitle to appropriate the transfers made in the initial rent-seeking contest. This can create further social costs.

The so-called low-level corruption can be limited through better administrative institutions, such as the wage structure and the monitoring of low level bureaucrats (Acemoglu and Verdier, 1998, 2000, Besley and McLaren, 1993, Laffont and Guessan, 1999). Moreover, the design of sanctions for corrupt behavior is crucial for effectively reducing corruption (Mookerjee and Png, 1995, Rose-Ackerman, 1975). Implicitly, this literature assumes principal-agent relations with benevolent principals. A more pessimistic view is offered in models where the government officials as well as the politicians are corruptible. Shleifer and Vishny (1993) show how the organization of public good provision (competition, monopoly, several independent monopolies) influences the level of corruption. When corruption occurs also on the top level of the government, the motivations of politicians, as well as the institutions that constrain them, are a crucial factor. ${ }^{5}$ Accordingly, democratic institutions could help to limit corruption. ${ }^{6}$

In democratic regimes, politicians only have incentives to implement anti-corruption policies if they encounter enough political support for such measures. When we observe persistent high corruption levels in democratic countries, we must then explain the absence of this political support. In our model, we argue that the lack of financial institutions makes larger parts of the population dependent on corruption. In contrast to the majority of models in the literature, we choose an integrated approach: We argue that administrative corruption spreads if corrupt officials have to pay an entry fee. To the best of our knowledge, the role of financing the entry fee has so far not been analyzed. When corrupt officials have to resort to other citizens to finance the entry fee, additional groups of voters have a stake in corruption. This reduces the political support for anti-corruption campaigns.

The paper is organized as follows: In section 2, we study corruption and the market for lucrative jobs in transition and developing countries. In section 3, we set up the basic model and discuss the differences between the cases with and without a functioning financial sector. In section 4, we develop the probabilistic voting model on anti-corruption policies. In section 5, we discuss the effects of financial institutions on corruption. Extensions to the model, the endogenous choice of the entry fee by the superior, and additional exposure to corruption of the entrepreneurial sector, are discussed in section 6. Section 7 concludes. All proofs are relegated to the appendix.

\footnotetext{
${ }^{5}$ Shleifer and Vishny (1998) coined the term "the grabbing hand": It describes rent-seeking governments which are constrained only by the political and economic institutions in their countries.

${ }^{6}$ However, generally, democratic institutions cannot abolish state capture. The political economy literature concerned with this issue points, among other explanations, to common pool problems that conceal the responsibilities of policy makers (Persson et al, 1997) or to distortions due to the influence of special interest groups (Coate and Morris, 1995).
} 


\section{Corruption and Entry Fees in Transition and Developing Coun- tries}

There is evidence from both developing and transition countries that bureaucrats who obtain a lucrative job pay entry fees. In turn, officials have to be bribed for a variety of services. Since the start of its policy initiative against corruption, the Worldbank has conducted several surveys addressing the issue. In the BEEPS (business environment and enterprize performance survey), firms in Eastern Europe and the former Soviet Union are asked for information about informal payments and the "time tax", the time spent dealing with regulatory issues (EBRD, 2002, Chpt. 2).

A survey conducted among 350 enterprizes in Georgia indicates that most instances of corruption occur in the following areas: tax and financial inspections, border crossing at customs, water and electricity services, fire and sanitary inspections, and contact with road police. According to this survey, 71 per cent of the enterprizes would be willing to pay higher taxes if corruption was eliminated. Those enterprizes that indicate their willingness to pay higher taxes would pay additional taxes of up to 22 per cent of their revenues in order to eliminate corruption. These figures indicate that the total amount of bribes that has to be paid by enterprizes must be substantial (Worldbank, 1998). This is reflected in Georgia's position in the Transparency International ranking of the corruption perception index. In 2002, Georgia was on rank 85 (together with Ukraine and Vietnam) of 102 countries listed.

For the officials, the bribes translate into high rents from office. The existence of entry fees for positions in the bureaucracy is well known not only among the officials but also in the general public. The entry fee increases with the amount of bribes that can be appropriated in a particular position. In Georgia, the percentage of public officials believed to have purchased their position exceeds 50 per cent for customs and tax inspectors. More than one third of the positions of natural resource licensers, judges, investigators, and prosecutors are believed to be purchased (Worldbank, 1998). ${ }^{7}$

The seminal article on the market for public office is Wade (1982). In several periods of fieldwork, he collected evidence for the "corruption system" found in the canal irrigation in India. ${ }^{8}$ There are two sources of revenue for the officials: First, they may embezzle money from the budget that each canal division gets for financing the maintenance work. Embezzlement often happens by colluding with the subcontractors who are employed for performing the maintenance work. Second, the irrigators pay the officials in order to assure the water supply either for the whole season or for emergencies (Wade, 1982, pp. 292). Those who benefit from the bribes are

\footnotetext{
${ }^{7}$ The Worldbank surveys show that petty corruption is more of a problem in Georgia and Albania whereas grand corruption is more serious in Latvia, where about 20 per cent of all ministerial positions are believed to be purchased.

${ }^{8}$ India is among the most corrupt countries of the world. In 2002, India was on rank 71 (together with Cote d'Ivoire, Honduras, Russia, Tanzania and Zimbabwe) of the Transparency International ranking of the corruption perception index.
} 
the Executive Engineers, who head a division at the irrigation department, and the Assistant Engineers, who are in charge of a sub-division. On average, an Assistant Engineer receives an additional annual income from bribes of about 3.5 times his official annual wage (Wade, 1982, p. 302). The official salary of an Executive Engineer is about 25 per cent higher than that of an Assistant Engineer. Each year, an Executive Engineer earns about 9 times his official annual salary from bribes (Wade, 1982, p. 293).

Senior officers and politicians appropriate part of the engineers' additional income by demanding an entry fee for assigning them a particular position. The entry fee that an engineer has to pay depends on the productivity of the area where the new position is located. In the uplands, it costs an Executive Engineer about three time his annual wage to get a position with a two-year tenure. In contrast, on the fertile deltas, the entry fee can be up to about 14 times his annual salary (Wade, 1982, p. 305).

We base our model on the observations made in India and Georgia, i.e., we take for granted that an entry fee for lucrative positions has to be paid. In our model, we show how the mode of financing the entry fee can influence the voting decisions of different groups of voters. This, in turn, may lead to different levels of political support for anti-corruption campaigns.

\section{Financing the Entry Fee}

For the basic setup of the model, we describe the economy and the financial institutions, as well as the interactions when these institutions are missing. We compare different cases: First, we look at an economic system without functioning financial institutions. Second, we introduce a functioning formal credit market. Whenever there is a formal credit market, the agents in the economy have the option to use the banking sector. We compare two scenarios: Banks may have access to a perfect screening technology or they may not be able to screen at all. We do not study the intermediate case.

\subsection{The Model}

The economy with total population size $N$ consists of three groups of citizens: The depositors $D$, the corrupt officials $K$, and the relatives $R$ of the corrupt officials. Each group has $\alpha_{J} N$, $J=\{D, K, R\}$, identical individuals, where $\alpha_{J}$ denotes the share of a particular group. Each citizen has the same initial endowment $A, A>0$. This endowment comprises wealth and income of each citizen, i.e. $A=W+w$. When the citizens do not embark on any additional economic activities, they stay with their initial endowment $A$. There is no depreciation.

Depositors. The depositors want to invest their endowment in order to earn some return on their assets. They can do this only on the formal credit market. ${ }^{9}$

Corrupt Officials. The citizens have to pay a bribe if they want to make use of any of the public services offered by the officials. Each corrupt official can collect a bribe $c, c \geq 0$ from a

\footnotetext{
${ }^{9}$ The reason for this is, for example, that there could be high transaction costs in the informal credit market. These can only be overcome by family ties. The depositors do not have relatives who want to borrow money.
} 
fraction $\sigma \in[0 ; 1]$ of all other citizens. The fraction of citizens who pays the bribe to an official depends on how many people want to make use of a certain public service. We assume the $\sigma$ to be exogenously given. Then, the total amount of bribes a corrupt official can collect amounts to $\sigma(N-1) c .^{10}$

There is a given number of positions in the bureaucracy. The group of citizens who obtained these positions is called the group $K$ of corrupt officials. ${ }^{11}$ Due to the corruption rent, these positions are so attractive that the superiors can demand an entry fee for each of them. The size of the entry fee $T(c)>0$ depends on the amount of rents that public servants can extract from the other citizens. We choose a simple linear specification, $T(c)=t c$, with $t>0$. The entry fee is collected by the superiors of the public officials. These are higher ranked officials in the bureaucracy. We take the number of corrupt officials as given in order to focus on how the mode of financing the entry fee influences the political choice of the corruption level $c .{ }^{12}$

In the basic model, the superiors are not included as agents. Thus, we exogenously assume the $t$. For the moment, we assume that the entry fee $t$ is set in such a way that the corrupt officials get at least a marginal payoff from corruption. For the reasoning of the model, it is important that the corrupt officials have a positive rent from corruption and therefore a political interest in corruption. A situation where competition for positions drives the entry fees up and the rents from corruption for the corrupt officials down to zero is excluded by assumption. We endogenize the superiors' choice of the size of the entry fee $T(c)$ in section 6 . When the superiors endogenously choose the entry fee, they have to take the participation constraints of the potential corrupt officials into account: $T(c)$ cannot be so high that it is unattractive to apply for the position. We show in section 6 that the superiors actually have the incentive to leave a positive rent from corruption to the corrupt officials in order to reduce the officials' support for anti-corruption policies.

We assume that the superiors are not able to directly influence the political decision-makers, i.e., the revenues from corruption cannot be used to finance electoral campaigns. Thus, the income from corruption does not give the superior any particular political weight. The superiors use the revenue from the entry fees for private expenditures. Again, this restriction is used to focus on the role of the financing of the entry fee for the persistence of corruption. ${ }^{13}$

\footnotetext{
${ }^{10}$ This is of course a simplification: In reality, some services and some positions might be more lucrative than others (see section 2).

${ }^{11}$ By demanding an entry fee, the superior ensures that only persons with the adequate skills apply for positions as public officials: People who are unable to extract bribes from their clientele will find the job in the bureaucracy unprofitable. Also, non-corruptible persons will find it unattractive to become officials. With this selection mechanism, the bureaucracy is composed only of corrupt officials. This may seem a very unrealistic setup. Yet, for the purpose of the model, the presence of additional non-corrupt officials would not alter the results as this group of voters would not have a positive stake in corruption.

${ }^{12}$ The superiors cannot choose the number of positions in order to maximize their profits from corruption. Incentives for the superiors to restrict entry to the public positions in order to collect higher rents would be another interesting topic of research.

${ }^{13}$ To model the political influence of the higher-rank officials as a function of their revenues from collecting
} 
Relatives. Relatives differ from the other depositors in that they have a corrupt official in their close family. This can be an advantage for them insofar as they then have the opportunity to invest on the informal credit market.

All groups of citizens suffer equally from corruption. The disutility from corruption is given by $-u(c)$, where $u(c)>0$. It does not only capture the costs of the bribe but also other negative aspects of corruption such as time lags in getting services, non-enforceability of services for which bribes have been paid and the psychologic costs involved. It is assumed that these costs grow with the level of corruption $c$, such that $\frac{\partial u(c)}{\partial c}>0$, and $\frac{\partial^{2} u(c)}{(\partial c)^{2}}>0$. Note that the corrupt officials suffer from corruption like all the others, as they need also other services except for the one where they are working. Most of the time, they are in the same situation as the rest of the population.

The time structure of the model is as follows: In period 1, the elections are held. In the elections, the level of corruption $c$ is determined. ${ }^{14}$ In period 2, the corrupt officials decide on the financing of the entry fee $T(c)$. In period 3, the corruption level realizes, the bribes are collected and individuals receive their payoffs. The time structure is summarized in figure 1 . Since the game is solved by backward induction, we start with the decision of how to finance the entry fee.

Figure 1: Time Structure

\begin{tabular}{l|l|l} 
Period 1 & Period 2 & Period 3 \\
\hline Election & $\begin{array}{l}\text { Decision on } \\
\text { financing T }\end{array}$ & $\begin{array}{l}\text { Corruption level realizes } \\
\text { Payoffs are realized }\end{array}$
\end{tabular}

\subsection{The Economy without Financial Institutions}

In this section, we study the case without financial institutions. There exists no formal credit market. We assume that depositors cannot participate in an informal credit market. For all groups, the utility functions are separably additive in the endowment $A$, possible benefits from corruption or other economic activities, and the disutility of corruption.

Depositors. When there are no financial institutions, the group of depositors has no possibility to invest their initial endowment: There is no credit market where they could lend their

the entry fees would distract attention from the main point of this model. In the lobbying literature, campaign expenditures are linked to policy outcomes (see Grossman and Helpman 2001). In the corruption literature, this would be a question of state capture. The type of corruption studied in this model is more correctly described by the concept of administrative corruption.

${ }^{14}$ The time structure of the election subgame is described in section 4 . 
money and, as they are not relatives of a corrupt official, they do not have access to the informal credit market. Thus, the depositors' utility function is composed of their initial endowment and of their losses from corruption. The utilities of depositors are given by: ${ }^{15}$

$$
U_{D}^{N}(c)=A-u(c)
$$

Corrupt Officials. The corrupt officials receive bribes of the amount of $\sigma(N-1) c{ }^{16}$ In order to get access to their jobs, the corrupt officials have to pay the entrance fee $T(c)=t c$ to their superior. To finance this fee, the corrupt officials need some funds in addition to their initial endowment $A$. We allow each corrupt official to borrow only from one relative. If this informal credit market is to be cleared, the group sizes of corrupt officials and relatives have to be equal, i.e., $\alpha_{K}=\alpha_{R}{ }^{17}$ We also assume that $A<T \leq 2 A$. This means that each corrupt official has to borrow some amount from his relative and that one relative has enough funds to lend the whole missing amount for the entry fee. Note that the superiors could always get at least a payment of $A$ from the corrupt officials. Then, the corrupt officials would not need external sources of financing. However, as the focus of this model is the effect of the different modes of the financing of the entry fee on the level of corruption, we exclude such a case by assumption.

The corrupt officials borrow $(t c-A)$ from the relatives and repay $\left(1+b^{N}\right)(t c-A)$. The equivalent to the interest rate on the informal credit market, $b^{N}$, is determined in a Nash bargaining game among the pairs of corrupt officials and relatives. We assume equal bargaining power of corrupt officials and relatives. The utility of the corrupt officials when there are no financial institutions is:

$$
U_{K}^{N}(c)=\sigma(N-1) c-\left(1+b^{N}\right)(t c-A)-u(c)
$$

Relatives. The relatives receive the interest rate $b^{N}$ on the amount of capital which they lend to their corrupt family member. Their utility is thus:

$$
U_{R}^{N}(c)=A+b^{N}(t c-A)-u(c)
$$

\footnotetext{
${ }^{15}$ The superscripts $N$ denote the utility levels in the case with no financial institutions.

${ }^{16}$ Note that certain restrictions have to be imposed on $\sigma$ to ensure that the revenues from corruption equal the sum of bribes paid in the economy. The revenues from corruption depend on how many individuals use each particular service. This is given by $\sigma$. The sum of bribes paid, in turn, depends on how many services each individual uses. This can be captured by a parameter $\phi$. The total revenues from corruption are $\sigma(N-1) c \alpha_{K} N$. These have to equal the sum of bribes paid by all citizens $c N \phi$. The restriction on $\sigma$ would then be $\sigma=\frac{\phi}{(N-1) \alpha_{K}}$. This model uses the disutility function $-u(c)$ to capture the costs from corruption for each individual. In this, the parameter $\phi$ can be thought to be implicitly included.

${ }^{17}$ For our model, this is the most restrictive case as the group of voters that potentially have a positive stake in corruption is minimized. If we allow for the possibility that each corrupt official borrows from several relatives, more voters receive a positive, albeit smaller, revenue from corruption. Only in the extreme case, with perfect competition among the relatives, their rent from corruption would be reduced to zero.
} 
When bargaining over $b^{N}$, corrupt officials and relatives have the same disagreement payoff: If negotiations break down, the corrupt officials have to stay depositors and are left with their endowment and the costs of corruption. The relatives have no possibility to invest their endowment and are left with the same utility level. We can state the following result for the bargaining game in the case without financial institutions:

Proposition 1 In the economy without functioning financial institutions, the relatives lend to the corrupt officials on the informal credit market and receive the interest rate $b^{N}$, i.e.,

$$
b^{N}=\frac{[\sigma(N-1)-t] c}{2(t c-A)} .
$$

Since, in the case without functioning financial institutions, corrupt officials and relatives share the net surplus from corruption and have the same disagreement payoff, their utility levels are the same:

$$
U_{K}^{N}(c)=U_{R}^{N}(c)=\frac{1}{2}[\sigma(N-1)-t] c+A-u(c)
$$

As discussed above, there must be a net surplus of corruption that can be split in bargaining, i.e., $[\sigma(N-1)-t] c>0$. Each party gets its disagreement payoff and a positive revenue on top of that. Otherwise, the positions in the bureaucracy would cease to be attractive. Therefore, in the case without functioning financial institutions the range of $t$ is defined by $A<t c<\sigma(N-1) c$.

\subsection{The Economy with Financial Institutions}

Next, we introduce financial institutions in the economy. To keep the analysis of the financial sector tractable, we study a small open economy. Therefore, the interest rate $r$ is determined by the world market and is identical for borrowing and saving. In the following, we distinguish two cases: In the first case, banks are able to screen the borrowers. As we will explain below, when banks have a screening technology, they deny credit to any borrower who intends to finance an entry fee for a position as a corrupt official. In the second case, banks are not able to detect corrupt officials and offer a pooling contract at a rate $r$.

Depositors. The depositors now can invest their initial endowment on the formal credit market. They still suffer from corruption. For both the case with screening and with pooling, their utility with a functioning credit market is thus: ${ }^{18}$

$$
U_{D}^{B S}(c)=U_{D}^{B P}(c)=(1+r) A-u(c)
$$

\subsubsection{Perfect Screening}

The reason why banks wish to exclude corrupt officials may be that they have committed themselves to a code of ethics. This code includes that they are wary to support any instances of

\footnotetext{
${ }^{18}$ When the four groups decide to use the formal credit market and go to the bank that offers screening contracts, their utilities are denoted with the superscript $B S$. When banks offer pooling credits, their utilities are denoted with the superscript $B P$. When they decide not to use the bank although a banking sector is present and functioning, we denote their utility with the superscripts $N B S$ or $N B P$, respectively.
} 
corruption. ${ }^{19}$ In the model, banks receive perfect signals about their creditors without incurring any costs. ${ }^{20}$ As a result, they offer credit only to non-corrupt investors on the world market at the interest rate $r$. Depositors and relatives have the opportunity to save at interest rate $r{ }^{21}$

Corrupt Officials. For the corrupt officials, the situation does not change much compared to the case without financial institutions as the banks exclude them from the formal credit market. The only way to finance the entry fee is to borrow from their relatives. However, the relatives now have the outside option to save at the bank at the rate $r$. We denote the bargaining outcome over the equivalent to the interest rate in the informal credit market in this case with $b^{B S}$. The utility of the corrupt officials when they borrow from their relatives is:

$$
U_{K}^{N B S}(c)=\sigma(N-1) c-\left(1+b^{B S}\right)(t c-A)-u(c)
$$

If the corrupt officials do not borrow from the relatives, they are not able to pay the entry fee and remain depositors. Therefore, their outside option amounts to $U_{K}^{B S}(c)=(1+r) A-u(c)$.

Relatives. The relatives have the choice to save at the bank or to lend to the corrupt officials. When they decide to lend to the corrupt officials, they earn the rate $b^{B S}$ on the amount that they lend to the corrupt officials. For the rest of their endowment, i.e., $(2 A-t c)$, they receive the rate $r$ from the bank. Their utility is:

$$
U_{R}^{N B S}(c)=A+b^{B S}(t c-A)+r(2 A-t c)-u(c)
$$

If the relatives save their whole initial endowment at the bank, their utility is $U_{R}^{B S}(c)=$ $(1+r) A-u(c)$.

We can state the following result for the bargaining game in the case without functioning financial institutions and screening:

Proposition 2 If banks are able to screen perfectly, the relatives lend to the corrupt officials on the informal credit market and receive the interest rate $b^{B S}$, i.e.,

$$
b^{B S}=\frac{[(N-1)] \sigma c-t c(1-r)-2 r A}{2(t c-A)} .
$$

After the bargaining, the utility functions in the situation with functioning financial institutions where banks have access to a perfect screening technology are the same for corrupt officials and relatives:

$$
U_{K}^{B S}(c)=U_{R}^{B S}(c)=\frac{1}{2}[\sigma(N-1)-(1+r) t] c+(1+r) A-u(c)
$$

\footnotetext{
${ }^{19}$ Many international banks subscribe to such a code of ethics. There, they commit themselves to refusing all interactions that could be linked to money-laundering activities. For an example, see www.imb.ru/en/about/ethics_code.htm.

${ }^{20}$ In practice, the screening process could, for example, involve that banks demand a business plan from potential borrowers in order to evaluate their investment projects. In the absence of a market for consumer credits, corrupt officials have no possibility to get credit as they are unable to provide a business plan.

${ }^{21}$ We do not consider the possibility that banks may only be able to screen partially. Including this would not lead to any substantially new results but to a hybrid of the results of the two extreme cases pooling and perfect screening.
} 
The equivalent to the interest rate on the informal credit market decreases with respect to the case without banks. Formally, $b^{B S}<b^{N}$ when the following inequality holds:

$$
(N-1) \sigma c-t c(1-r)-2 r A<[\sigma(N-1)-t] c \Leftrightarrow r(t c-2 A)<0
$$

This is always true. Given our assumption that $t c<2 A$, the existence of a functioning banking sector with screening always reduces the relatives' revenue from corruption. The relatives now have an additional opportunity to save. Whatever they do not lend to the corrupt officials, they can save at the bank at the rate $r$. Relatives and corrupt officials still have equal disagreement payoffs as they both become depositors when the negotiations break down. In symmetric Nash bargaining, the relatives thus have to compensate the corrupt officials for their additional gain from saving at the bank of $r(2 A-t c)$ by lending to them at a lower interest rate.

The presence of banks sets an implicit lower bound for the interest rate on the informal credit market: The relatives will not agree to lend to the corrupt officials at a rate lower than $r$. When bargaining over the net surplus from corruption, both parties take these relatives' opportunity costs of not saving at the bank into account. The gross surplus of corruption is diminished by $(1+r) t c$. Now, the maximum for $T$ is given by $[\sigma(N-1)-(1+r) t] c>0$. Therefore, in the case with functioning financial institutions the range of $t$ is defined by $A<t c<\frac{\sigma(N-1)}{1+r} c$.

\subsubsection{No Screening Possible}

When banks cannot screen, they serve all borrowers and offer a pooling contract at the rate $r$. Therefore, corrupt officials and relatives possess additional opportunities to lend or borrow.

Corrupt Officials. When bargaining on the informal credit market, both the relatives and the corrupt officials now have the outside option to use the formal credit market. This affects their disagreement utilities. We denote the bargaining outcome in presence of a bank that offers a pooling credit with $b^{B P}$. Then, the utility of the corrupt officials is

$$
U_{K}^{N B P}(c)=\sigma(N-1) c-\left(1+b^{B P}\right)(t c-A)-u(c)
$$

The corrupt officials can borrow the amount $t c-A>0$ from the bank. For this, they have to pay the interest rate $r$. When in office, the corrupt officials earn the benefits from corruption by collecting a bribe from each individual in the economy. The utility of the corrupt officials when they borrow on the formal credit market is:

$$
U_{K}^{B P}(c)=\sigma(N-1) c-(1+r)(t c-A)-u(c)
$$

Relatives. The relatives can invest in the formal credit market or stay in the informal credit market and lend to the corrupt officials. When the relatives decide to stay in the informal credit market and lend to the corrupt officials, they receive the rate of the informal credit market $b^{B P}$ for the amount $(t c-A)$ that they lend to the corrupt officials. They can save the rest of their endowment, $2 A-t c$, at the bank at the rate $r$. When the relatives decide to stay in the informal credit market and lend to corrupt officials, their utility is:

$$
U_{R}^{N B P}(c)=A+b^{B P}(t c-A)+r(2 A-t c)-u(c)
$$


When the relatives invest only in the formal credit market, they get the same utility as the depositors, i.e., $U_{R}^{B P}(c)=(1+r) A-u(c)$.

For a given interest rate $r$, we can analyze the incentives of the corrupt officials and relatives to participate in the formal credit market. Note that the depositors always participate in the formal credit market as they have no other investment opportunities.

In the bargaining game, the disagreement payoffs of both corrupt officials and relatives are given by $U_{K}^{B P}(c)$ and $U_{R}^{B P}(c)$. Since the disagreement payoffs differ for the two parties, their incentives to make concessions in the bargaining game change, too. In the case where banks offer pooling contracts, we can state the following result:

Proposition 3 In the economy with functioning financial institutions where banks offer pooling contracts, the Nash bargaining solution yields $b^{B P}=r$. Bargaining does not create any additional surplus. The only interest rate in this economy is the world market rate $r$.

When bargaining on the informal credit market, both groups thus receive exactly the same utility level as when they use the bank. Individually, each corrupt official is indifferent between using the bank or borrowing from his relative. The reason for that is that one single individual does not have any influence on the corruption level that is determined in the elections. Given that their individual decision does not have an impact on the overall corruption level, the corrupt officials are indifferent between staying in the informal credit market and using the formal credit market. Note that it is irrelevant whether or not the corrupt officials actually use the bank or not. The relatives always get the same utility level. Thus, their interest in the level of corruption remains unchanged.

\section{Voting on Anti-Corruption Policies}

In this section, we focus on the questions of how the level of corruption is determined in the political process and how the political support for low or high corruption levels determines the incentives of politicians to fight corruption. We develop a model of probabilistic voting. ${ }^{22}$ The corruption level is the policy platform on which the candidates run for office. We abstract from eventual difficulties in implementing the politically desired corruption level. The candidates choose the corruption level that maximizes their chance of winning the elections. This depends on the utilities that the voters derive from this level of corruption.

A probabilistic voting model has the advantage of incorporating the voters' responsiveness to marginal policy changes. In contrast to a median voter model, it does not only count the individual votes but takes into account how much this policy matters for the different groups of voters. In a median voter model, the group size would in a trivial way determine the outcome of a low or high corruption level, depending on the position of the median voter. With a probabilistic voting model, we can explain high corruption levels even when a large fraction

\footnotetext{
${ }^{22}$ We use a specification of the probabilistic voting models similar to the one suggested by Persson and Tabellini (2001).
} 
of the voters suffers from corruption: By discussing several assumptions on the responsiveness of the different groups of voters, we allow for outcomes where a minority of voters influences the equilibrium corruption level. This is the case when the victims of corruption have diverse positions on other policy issues or strongly differing ideologies.

Furthermore, probabilistic voting models have the characteristic that they yield a unique equilibrium outcome: If the objective function of the candidates is strictly concave, the candidates in equilibrium choose the same uniquely defined policy. In order to compare different policy outcomes for the cases without and with functioning financial institutions, this characteristic is very useful.

The groups of voters are of a fraction $\alpha_{J}$ of the total population with $J=\{D, K, R\}$ and $\sum_{J} \alpha_{J}=1$. In the basic model, we exclude the superiors from voting. This is changed in section 6. There are two candidates, $X$ and $Y$, running for election. We assume that candidates strive to get the majority of votes in the population. ${ }^{23}$ The candidate who wins the majority of votes implements his proposed policy. In addition to their utility from the corruption policy $U_{J}(c)$, each voter bases her vote on her ideology. This ideology component can be a second policy dimension, where the candidates are not able to make credible commitments but are expected to implement their individually preferred policy. It might thus capture political ideology or other political interests that are not easily switched. Each citizen has an ideologic preference for one or the other candidate. Election promises of the candidates are not going to change these preferences.

Within each group, the individual ideologies differ, so that groups are not homogenous. For example, an individual of group $J$ may be biased towards candidate $X$ because of her opinion on an interventionist economic policy, whereas another individual from the same group may be biased towards candidate $Y$ because she prefers a free market economy. This ideological bias is captured by the individual-specific parameter $s_{i J}$ which measures the ideological preference of voter $i$ of group $J$ for candidate $Y$. The $s_{i J}$ can be positive or negative. A positive value implies that the voter is biased in favour of candidate $Y$ whereas a negative value shows a bias in favor of candidate $X$. Generally, the more $s_{i J}$ differs from 0 , the stronger is the ideology component in the citizen's voting decision. A citizen with a strong ideologic bias is less responsive to changes in the policy platforms $c_{X}$ and $c_{Y}$ announced by the candidates. The individual ideology parameters are uniformly distributed according to $s_{i J} \sim\left[-\frac{1}{2 S_{J}} ; \frac{1}{2 S_{J}}\right]$.

Taking into account all the components which influence the election decision of voter $i$ in group $J$, voter $i$ prefers candidate $X$ if and only if:

$$
U_{J}\left(c_{X}\right)>U_{J}\left(c_{Y}\right)+s_{i J}
$$

The time structure for the voting game is as follows: First, the two candidates announce their policy platforms $c_{X}$ and $c_{Y}$. By assumption, they are able to commit perfectly to imple-

\footnotetext{
${ }^{23}$ Similarly, we could assume that the candidates maximize their probabilities of winning the elections, that is, the probabilities of getting more than half of the vote share. As shown in Lindbeck and Weibull (1987), the maximization problem for the candidates is then similar to the problem of maximizing the vote shares under fairly general conditions. These conditions are fulfilled by the assumptions in this model.
} 
menting these policy proposals. The candidates know the voters' policy preferences $U_{J}(c)$ and the distributions for $s_{i J}$. They do not know the realizations of the $s_{i J}$. After the announcement of the policy platforms, candidates observe the realizations of these values and elections are held. The candidate with the majority of votes wins the elections. He implements the policy platform that he has announced. The time structure of the election subgame is summarized in figure 2 .

Figure 2: Time Structure of the Elections

\begin{tabular}{l|l|l|l} 
Stage 1 & Stage 2 & Stage 3 & Stage 4 \\
\hline$c_{X}$ and $c_{Y}$ & $s_{i J}$ realize & Election & $c^{*}$ is \\
are announced & & & implemented
\end{tabular}

In a probabilistic voting model, candidates compete by catering to the groups of voters who are most responsive to policy changes. ${ }^{24}$ That is, candidates are interested in identifying how easily voters of a group will switch to vote for them in response to a marginal policy change. For each group, the "swing voter", i.e., the voter who is exactly indifferent between voting for candidate $X$ or $Y$, is identified by the condition:

$$
s_{J}=U_{J}\left(c_{X}\right)-U_{J}\left(c_{Y}\right)
$$

All voters in a group $J$ with $s_{i J}$ lower than $s_{J}$ prefer candidate $X$, all others prefer candidate $Y$. Integrating over the ideologic biases within groups and summing over all groups gives the vote share for candidate $X$ as a function of the policy platforms $c_{X}$ and $c_{Y}:^{25}$

$$
v_{X}=\sum_{J} \alpha_{J} S_{J}\left(s_{J}+\frac{1}{2 S_{J}}\right)=\sum_{J} \alpha_{J} S_{J}\left(U_{J}\left(c_{X}\right)-U_{J}\left(c_{Y}\right)+\frac{1}{2 S_{J}}\right)
$$

Each candidate chooses her policy platform $c$ in order to maximize her vote share $v$. The vote share is a continuous and differentiable function of the distance between the two policies announced by the candidates. When the objective functions of the candidates are strictly concave in $c$, we get a unique equilibrium that maximizes the vote share for each candidate (see Coughlin and Nitzan 1981, or Lindbeck and Weibull, 1987). In equilibrium, we have complete convergence of the policy platforms:

\footnotetext{
${ }^{24}$ Dixit and Londregan (1996) discuss the importance of a group's responsiveness to a policy change in the context of redistributive politics. They measure a voter's responsiveness to redistributive politics by two parameters: One captures the strength of the ideological preferences of the voter. The other parameter measures the marginal utility changes due to a policy change. In our model, this is captured by $S_{J}$ and the first derivatives of the utility functions $\frac{\partial U_{J}(c)}{\partial c}$, respectively.

${ }^{25}$ For candidate $Y$, the vote share is derived similarly by integrating over all voters with a $s_{i J}$ higher than $s_{J}$ and summing over all groups: $v_{Y}=\sum_{J} \alpha_{J} S_{J}\left(\frac{1}{2 S_{J}}-s_{J}\right)=\sum_{J} \alpha_{J} S_{J}\left(U_{J}\left(c_{Y}\right)-U_{J}\left(c_{X}\right)+\frac{1}{2 S_{J}}\right)$.
} 
Proposition 4 In the elections, both candidates choose the same policy platform $c^{*}$. For each parameter constellation, there exists a unique $c^{*}$. It is determined by the condition

$$
\frac{\partial v}{\partial c}=0 \Longleftrightarrow \sum_{J} \alpha_{J} S_{J} \frac{\partial U_{J}(c)}{\partial c}=0
$$

In order to derive the equilibrium corruption levels, we plug in the utility functions of all groups. Then, the corruption levels can be compared for the cases without and with financial institutions. This is done in the next section.

\section{Results: The Effect of Financial Institutions on the Corrup- tion Level}

In this section, we derive the equilibrium corruption levels for the cases without and with financial institutions. We then compare the equilibrium corruption levels in order to derive whether and under which conditions functioning financial institutions can reduce corruption.

\subsection{Corruption Level without Financial Institutions}

The following lemma describes the policy choice without financial institutions:

Lemma 1 If no banks exist, the political parties offer a policy platform that determines an equilibrium corruption level $c_{N}^{*}$, implicitly defined by

$$
\frac{\partial u\left(c_{N}^{*}\right)}{\partial c}=\frac{\left(\alpha_{R} S_{R}+\alpha_{K} S_{K}\right)\left[\frac{\sigma(N-1)-t}{2}\right]}{\sum_{J} \alpha_{J} S_{J}} .
$$

with $J \in\{D, K, R\}$.

On the left hand side, we see the marginal disutility from corruption. It is the same for all groups. In the denominator of the right hand side, we find the groups that suffer from corruption. As all citizens suffer equally from corruption, this is the sum over all groups, weighted with the political responsiveness of the groups. The utility components in the numerator of the left hand side stem from those groups that have a positive interest in corruption: The relatives, whose earnings on the informal credit market depend positively on the corruption level, and the corrupt officials, who get a positive surplus from their job. The equilibrium corruption level decreases as the entry fee increases. The more the corrupt official has to pay for his job, the lower is the net surplus of corruption. Therefore, the relatives and the corrupt official have a lower marginal benefit from an increasing corruption level and are more supportive of anti-corruption policies. Note that the depositors only show up in the denominator as they do not have any positive revenue from corruption.

\subsection{Corruption Level with Financial Institutions}

Next, we compare this outcome to the equilibrium corruption level with functioning financial institutions. 


\subsubsection{Perfect Screening}

The following lemma describes the policy choice if banks screen their borrowers:

Lemma 2 If banks possess a perfect screening technology, the political parties offer a policy platform that determines an equilibrium corruption level $c_{B S}^{*}$, implicitly defined by

$$
\frac{\partial u\left(c_{B S}^{*}\right)}{\partial c}=\frac{\left(\alpha_{R} S_{R}+\alpha_{K} S_{K}\right)\left[\frac{\sigma(N-1)-(1+r) t}{2}\right]}{\sum_{J} \alpha_{J} S_{J}} .
$$

Corrupt officials and relatives still use the informal credit market. Since $t c<2 A$, relatives use both the informal and the formal financial markets as they save the part of their endowment which they do not lend to the corrupt officials at the bank. The relatives have a positive stake in corruption because they lend to the corrupt officials on the informal credit market.

However, the relatives face a coordination problem: If they could coordinate on saving at the bank, this would reduce the political support for corruption and would lead to a lower equilibrium corruption level. Individually, it is optimal for each relative to lend to a corrupt official at the rate $b^{B S}$ : If all other relatives also lend to corrupt officials, the corruption level is high anyway. Similarly, the corruption level remains low if all other relatives save at the bank, even if a single relative decides to lend to a corrupt official. As the effect of one voter on the total political support for anti-corruption policies is negligible, the individual decision to stay in the informal credit market does not alter the equilibrium corruption level.

\subsubsection{No Screening Possible}

The following lemma describes the policy choice if banks are not able to detect the group of corrupt officials:

Lemma 3 If banks offer a pooling contract, the political parties offer a policy platform that determines an equilibrium corruption level $c_{B P}^{*}$, implicitly defined by

$$
\frac{\partial u\left(c_{B P}^{*}\right)}{\partial c}=\frac{\alpha_{K} S_{K}[\sigma(N-1)-(1+r) t]}{\sum_{J} \alpha_{J} S_{J}} .
$$

Now, only the corrupt officials get a positive rent from corruption. The relatives are missing from the numerator of the expression as they do not anymore have a positive stake in corruption. They receive the interest rate $r$ on their total asset endowment. Note again that it is irrelevant whether the corrupt officials use the bank or not.

The corrupt officials are in a prisoners' dilemma-like situation. In the aggregate, they would prefer to use the informal credit market and borrow from their relatives while giving them a higher interest rate than the bank. They would then have allies in the elections: If relatives had a stake in corruption, they would vote against possible anti-corruption measures. Individually, however, the strategy to win over a relative by offering him a rate $b^{B P}>r$ is not optimal for the corrupt officials: Suppose that all corrupt officials are borrowing from the bank. Official $i$ has no incentive to switch to the informal credit market and offer a rate higher than $r$ to his relative. 
The relative would agree to lend to the corrupt official when offered a higher rate than from the bank. Yet, the corrupt official would only win over one voter to the pro-corruption side. This one vote will not change the corruption level chosen by the politician. Next, suppose that all other corrupt officials borrow from their relatives at a rate $b^{B P}>r$. Then, it pays for official $i$ to switch to the formal credit market because he can then borrow at a lower rate. Furthermore, the corruption level is not lowered when all others stay in the informal credit market. Each corrupt official individually has the incentive to switch to the formal credit market or to lower the rate he offers to the relative to $b^{B P}=r$. Therefore, the relatives will not get any additional surplus from lending in the informal credit market. This means that the corrupt officials cannot coordinate to give the relatives a stake in corruption and remain the only group of voters with a positive interest in corruption.

\subsection{Impact of Financial Institutions on Corruption Level}

We can now compare the corruption levels for the cases with and without banks.

Proposition 5 If banks possess a perfect screening technology, the corruption level with functioning financial institutions is always lower than the corruption level without financial institutions,i.e., $c_{N}^{*}>c_{B S}^{*}$.

In the case without banks as well as in the case with banks that are able to perfectly screen, the entry fee is financed via the informal credit market. Corrupt officials and relatives share the revenues from corruption. Why does the existence of a functioning banking sector then decrease the equilibrium corruption level? If banks possess a perfect screening technology, the relatives have the option to save at the bank. Thus, they incur some opportunity costs if they decide to lend to their relatives. The higher the entry fee, the higher are these foregone returns on the bank deposits. When sharing the surplus from corruption, the corrupt officials and the relatives take these opportunity costs into account. For both groups, this decreases the marginal net benefit from corruption. Both groups are then less responsive to a change in the corruption level in the situation with banks and screening than in the situation without banks. As a consequence, the politicians cater less to these groups. The equilibrium corruption level is reduced.

What happens if banks are unable to screen and the corrupt officials have access to the formal credit market?

Proposition 6 If banks offer a pooling contract, the corruption level with functioning financial institutions is lower than the corruption level without these institutions, i.e., $c_{B P}^{*}<c_{N}^{*}$, if and only if

$$
\alpha_{K} S_{K}\left[\frac{\sigma(N-1)-t}{2}-r t\right]<\alpha_{R} S_{R} \frac{\sigma(N-1)-t}{2} .
$$

All costs and benefits from corruption are weighted with the political importance of the groups of voters, that is, the group size $\alpha_{J}$ and the group's political responsiveness $S_{J}$. The higher $S_{J}$, the more swing voters does a group have and the more do the politicians cater to this group. Whenever the corrupt officials' net marginal benefits of corruption with banks and 
pooling, weighted with the political importance of corrupt officials, are smaller than the relatives' net marginal benefits of corruption without banks, weighted with the political importance of the relatives, the introduction of a banking system leads to a reductions of the corruption level in the economy. The existence of banks with pooling increases the voters' support of anti-corruption policies.

The left hand side of condition (22) shows the marginal net benefits of the corrupt officials for the case when a functioning banking system is in place. All revenues from corruption are reaped by the corrupt officials. With respect to the case without financial institutions, they receive an additional half of the surplus from corruption, $\frac{\sigma(N-1)-t}{2}$. The reason is that they can now finance the entry fee via the bank. Without financial institutions, they had to borrow from their relatives and share the surplus from corruption in order to get credit from them. Equivalently, if they still borrow from the relatives, they do not have to give the relatives an additional surplus over the world market interest rate $r$. With a banking system, they have marginal costs for financing the entry fee of $r t$.

On the right hand side, we see why the relatives cease to be supporters of high corruption levels when a banking system is in place: With banks that offer pooling contracts, the relatives lose their half of the net return on corruption which they would receive without a banking system. Instead, they earn the rate $r$ on their endowment $A$, which is independent of the corruption level.

With our assumption $\alpha_{K}=\alpha_{R}$, we simplify condition $(22)$ to $S_{R}>S_{K}\left(1-\frac{2 r t}{\sigma(N-1)-t}\right)$. We know from the corrupt officials' participation constraint that $\sigma(N-1)-t>0$ and therefore $1-\frac{2 r t}{\sigma(N-1)-t} \leq 1$. Consider first the case where both groups have the same responsiveness to a marginal policy change, that is $S_{K}=S_{R}$. It is then clear that financial institutions lead to a lower equilibrium corruption level: In the presence of a banking sector with pooling, the relatives lose all their gains from corruption and become strict supporters of anti-corruption policies. The corrupt officials, in turn, gain from the presence of banks as they do not have to share the returns from corruption with the relatives. On the other hand, they also lose from having to pay the interest rate to the bank. In total, the corrupt officials' marginal gains from corruption due to the banking system are lower than the marginal gains of the relatives in the case without banks. With banks, the relatives are stronger opponents of an increase of the corruption level than the corrupt officials are supporters of such an increase. If both groups have equal political power, this results in a lower corruption level in the economy where banks offer pooling contracts.

This effect is reinforced for $S_{K}<S_{R}$. In this case, the relatives are more responsive to marginal changes in the policy variable than the corrupt officials. This is plausible when the anticorruption campaign is publicly advertised. Then, the relatives see that there is the opportunity to vote against corruption. Being part of the corrupt system, the corrupt officials will also without advertising attach a high importance to the issue. The political responsiveness, or the importance that voters attach to anti-corruption policies, can be increased when the issue receives a large public attention, for example, when the news media publishes investigations on corrupt government officials. ${ }^{26}$

\footnotetext{
${ }^{26}$ Brunetti and Weder (2003) show empirically that an independent press significantly decreases corruption levels. The reason they give is that corrupt behavior by government officials is more likely to be uncovered by a
} 
When the corrupt officials have a larger political influence than the relatives, i.e., when $S_{K}>S_{R}$, financial institutions could also make the situation worse and increase the equilibrium corruption level. The corrupt officials could be more responsive to announced changes in the corruption level as they are the main part of the corrupt system (in a way, their living depends on it). In such a case, the politicians respond more to the group of corrupt officials as it then has more swing voters than the group of relatives. For $t<\frac{\sigma(N-1)}{1+2 r}$ and $S_{K}>S_{R}$, it could happen that a banking system with pooling increases the corruption level in the economy. The advantage of a banking sector with pooling for the corrupt officials is that they can finance the entry fee via the bank. They do not have to share the returns form corruption with the relatives. This makes them desire a higher corruption level in the presence of banks that offer pooling contracts. In this case, the introduction of a banking sector would promote corruption. Note that for $t>\frac{\sigma(N-1)}{1+2 r},\left(1-\frac{2 r t}{\sigma(N-1)-t}\right)<0$, and a banking sector with pooling always decreases the equilibrium corruption level, irrespective of the relative influence of the groups of voters.

Note that the depositors do not have any influence in the decision for a lower or higher corruption level in the two different economic settings. As they always only suffer from corruption, their utilities enter the first order condition for the optimal policy choice exactly in the same way in the cases with and without financial institutions. The level of corruption is lower than if they were not considered by the candidates. For a move from one situation to the other, however, they do not play a role, regardless of their share in the population $\alpha_{D}$ or their political responsiveness $S_{D}$.

We can conclude that a financial sector where banks are able to screen perfectly and commit to a code of ethics unambiguously reduces the equilibrium corruption level. If banks can only offer pooling contracts, it depends on the political power of the different groups of voters whether the corruption level in the economy is reduced or not: In most cases, the presence of functioning financial institutions decreases corruption. Only if banks are unable to screen and the political influence of the corrupt officials compared to that of the relatives is very high, banks can have a negative effect on the political support for anti-corruption policies.

\section{Extension: Endogenizing the Entry Fee}

So far, the superiors of the corrupt officials have been left out of the picture. The model focussed entirely on the implications of the financing of the entry fee, taking its size as given. The entry fee can be endogenized by modelling the superiors of the corrupt officials as a group of citizens who participate in the political process. We assume that there is a group of superiors $\alpha_{S}$, where $\alpha_{S}<\alpha_{K}$. The population size $N$, which, in the basic model, did not include the superiors, is now increased by the group of superiors. The total population is thus some $N^{\prime}>N$. Each superior collects entry fees from several corrupt officials. The total number $\alpha_{K} N^{\prime}$ of corrupt officials is distributed evenly over all superiors, so that each superior collects entry fees from a proportion $\frac{\alpha_{K}}{\alpha_{S}}$ of corrupt officials.

free press. 
Unlike everyone else in the economy, the superiors do not suffer from corruption. This assumption is plausible: Being upper level bureaucrats, the superiors could be privileged in several ways, so that they are exempt from paying bribes in order to get public services. To assume costs of corruption also for the superiors would only make the calculations more cumbersome without adding any new insights. As the superiors do not pay bribes, the population size $N$ that determines the income from corruption, $\sigma(N-1) c$, is the same as in the basic model. The superiors' utility is:

$$
U_{S}(c)=\frac{\alpha_{K}}{\alpha_{S}} t c(t)
$$

All superiors are identical and choose the same entry fee in equilibrium. There is no competition between the superiors for the corrupt officials as the number of corrupt officials and positions is fixed and all corrupt officials have equal ability. Thus, each superior can behave in a monopolistic way. We further assume that the superiors do not face a coordination problem and are able to act as one monopolist on the market for lucrative positions in the economy. This is plausible as the superiors are a small group. ${ }^{27}$ Otherwise, the incentives to free-ride among the superiors would destroy the rents from corruption. For each individual superior, it would then be better to extract the whole rent from corruption by choosing a high entry fee, given that the other superiors leave a positive rent from corruption to the corrupt officials. This would preserve a high corruption level while the individual superior would increase his gains from corruption. In equilibrium, these individual incentives would lead to a full extraction of corruption rents from the corrupt officials, even though the superiors are able to anticipate that this leads to a low (or in the extreme case zero) corruption level in the elections. ${ }^{28}$ For the present model, we neglect such considerations.

For reasons of tractability, we introduce a specific disutility function of corruption for all groups of voters except for the superiors: $-u(c)=-\frac{1}{2} c^{2}$. This enables us to explicitly solve for the equilibrium corruption levels.

It is important to fix the time structure of the game: We introduce the choice of $t$ as an additional stage before the elections. The rest of the game evolves like in the basic model. Thus, in the bargaining and the elections, the agents take the entry fee $t$ as given. When choosing $t$, the superiors can anticipate the following behavior in the election and the bargaining stages. ${ }^{29}$

\footnotetext{
${ }^{27}$ Coordination problems would not arise at all if we had only one monopolistic superior. Likewise, the group of superiors could select one of them to decide on the size of the entry fee.

${ }^{28}$ The corruption level could still be positive due to the superiors' own positive interest in corruption. However, the superiors are a rather small group of voters. To grant them very high political influence would mean to leave the framework of a probabilistic voting model. There are other models, such as lobbying models which capture large political influence by small groups in a better way. In some countries, like the Ukraine, the superiors seem to control substantial parts of the political process. This surely is an interesting topic for future research.

${ }^{29} \mathrm{~A}$ reverse time structure, where the elections are held first and the superiors choose the entry fee after that would lead to time inconsistency problems: For a given corruption level, the superiors will always want to extract all the surplus from corruption from the corrupt officials. This leaves corrupt officials and relatives without a positive rent from corruption. For the extreme case, where the superiors have no political power, this would lead
} 
The time structure is summarized in figure 3 .

Figure 3: Time Structure with Endogenous Entry Fee

\begin{tabular}{l|l|l|l} 
Period 1 & Period 2 & Period 3 & Period 4 \\
\hline Choice of & Election & $\begin{array}{l}\text { Decision on } \\
\text { financing } T\end{array}$ & $\begin{array}{l}\text { Corruption level realizes } \\
\text { Payoffs are realized }\end{array}$
\end{tabular}

In the first period, the superiors choose the entry fee, anticipating the subsequent behavior of the corrupt officials and the relatives in the election and the bargaining stages. Therefore, from the point of view of the superiors, the equilibrium corruption level $c^{*}$ depends on the size of the entry fee, $t$. In this model, we get a linear relationship between corruption level and entry fee. The first order condition for the superiors' problem is:

$$
c(t)=-t \frac{\partial c}{\partial t}
$$

Backward induction gives us the bargaining outcome and the equilibrium corruption levels dependent on $t$, including in addition, with respect to the basic model, the political interests of the superiors. The superiors can, in their optimization calculus, anticipate the equilibrium corruption outcome. In the following, equilibrium corruption levels, and the equilibrium entry fees are derived for each of the three cases: no financial institutions, financial institutions with pooling and with perfect screening. Then, the resulting corruption levels for the different financial systems are compared.

Using the specification $-u(c)=-\frac{1}{2} c^{2}$ with lemmas 1,2 , and 3 , we can descibe the equilibrium corruption levels:

Lemma 4 With the endogenous choice of the entry fee, and for $J \in\{D, K, R\}$, the equilibrium corruption levels are, for the case without financial institutions:

$$
c_{N}^{*}(t)=\frac{\left(\alpha_{R} S_{R}+\alpha_{K} S_{K}\right) \frac{\sigma(N-1)-t}{2}+S_{S} \alpha_{K} t}{\sum_{J} \alpha_{J} S_{J}}
$$

for the case with financial institutions with screening:

$$
c_{B S}^{*}(t)=\frac{\left(\alpha_{R} S_{R}+\alpha_{K} S_{K}\right) \frac{\sigma(N-1)-(1+r) t}{2}+S_{S} \alpha_{K} t}{\sum_{J} \alpha_{J} S_{J}}
$$

to an equilibrium corruption level of zero and thus to zero revenues for the superiors. To grant the superiors large political powers in such a setting is outside the scope of this model. As mentioned before, this should be addressed in a political rent-seeking framework instead of a probabilistic voting model. The question is left for future research. 
and for the case with financial institutions with pooling:

$$
c_{B P}^{*}(t)=\frac{\alpha_{K} S_{K}(\sigma(N-1)-(1+r) t)+S_{S} \alpha_{K} t}{\sum_{J} \alpha_{J} S_{J}} .
$$

With respect to the basic model, the equilibrium corruption levels for a given $t$ are increased by the positive gains from corruption of the superiors, weighted with their political responsiveness $S_{S}$. Now, there is an additional group of voters with a positive interest in corruption: The superiors have a marginal benefit from corruption of $\alpha_{K} t$. This is weighted with the political influence parameter of the superiors, $S_{S}$. Note that we still have $\sum_{J} \alpha_{J} S_{J}$ with $J=\{D, K, R\}$, as the superiors do not suffer from corruption.

The superiors can take this political equilibrium into account when deciding on how to set the entry fee $t$ :

Lemma 5 When maximizing their revenue from the entry fee, the superiors choose the following sizes of the entry fee $t$, depending on the presence of a financial system. For for the case without financial institutions:

$$
t_{N}^{*}=\frac{\left(\alpha_{R} S_{R}+\alpha_{K} S_{K}\right) \sigma(N-1)}{2\left(\alpha_{R} S_{R}+\alpha_{K} S_{K}\right)-4 S_{S} \alpha_{K}}
$$

for the case with financial institutions with screening:

$$
t_{B S}^{*}=\frac{\left(\alpha_{R} S_{R}+\alpha_{K} S_{K}\right) \sigma(N-1)}{2(1+r)\left(\alpha_{R} S_{R}+\alpha_{K} S_{K}\right)-4 S_{S} \alpha_{K}}
$$

and for the case with financial institutions with pooling:

$$
t_{B P}^{*}=\frac{\alpha_{K} S_{K} \sigma(N-1)}{2(1+r) \alpha_{K} S_{K}-2 S_{S} \alpha_{K}} .
$$

We can see from these expressions that $t$ depends on the size $\alpha_{J}$ and on the political influence $S_{J}$ of those groups of voters that profit from corruption, namely corrupt officials, relatives, and superiors. Note that in the presence of banks, $t$ is diminished as the interest rate $r$ offered by the bank shows up in the denominator: In their choice of $t$, the superiors internalize that the outside options for corrupt officials and relatives to borrow and save at the bank reduce their net surplus from corruption.

We can use the results for $t$ to derive the equilibrium corruption levels. When comparing the equilibrium corruption level for the case without financial institutions with the cases where we have financial institutions, we find that our main results hold. The results are robust to the introduction of an endogenous choice of the entry fee.

Proposition 7 When the superiors endogenously choose the entry fee $t$, functioning financial institutions always reduce the equilibrium corruption level for the case where banks have access to a perfect screening technology, i.e., $c_{B S}^{*}<c_{N}^{*}$. For the case where banks offer pooling credits, financial institutions decrease the equilibrium corruption level, i.e., $c_{B P}^{*}<c_{N}^{*}$, if and only if:

$$
\alpha_{R} S_{R}>\alpha_{K} S_{K}\left[\frac{(1+r) S_{K}^{2}+S_{S}^{2}-(2+3 r) S_{K} S_{S}}{(1+r) S_{K}^{2}+S_{S}^{2}-(2+r) S_{K} S_{S}}\right]
$$


While the results of the basic model hold in the setting with the endogenous choice of the entry fee, the mechanisms that lead to these results are now different. This is particularly clear for the case with financial institutions with screening. Financial institutions with screening reduce the equilibrium corruption level. In the basic model, this was due to the reduction of the rents from corruption for relatives and corrupt officials: They take into account the opportunity costs for the relatives as they cannot get the interest $r$ on the part of their endowment that they lend to the corrupt officials. With the endogenous choice of the entry fee, the reason for this result is the lower revenue from corruption for the superior in the presence of financial institutions. Look at the equilibrium corruption levels $c_{N}^{*}$ and $c_{B S}^{*}$ :

$$
c_{N}^{*}=\frac{\left(\alpha_{R} S_{R}+\alpha_{K} S_{K}\right)\left[\frac{\sigma(N-1)}{2}-\frac{\left(\alpha_{R} S_{R}+\alpha_{K} S_{K}\right) \sigma(N-1)}{2\left(\alpha_{R} S_{R}+\alpha_{K} S_{K}\right)-4 S_{S} \alpha_{K}}\right]+\frac{S_{S} \alpha_{K}\left(\alpha_{R} S_{R}+\alpha_{K} S_{K}\right) \sigma(N-1)}{2\left(\alpha_{R} S_{R}+\alpha_{K} S_{K}\right)-4 S_{S} \alpha_{K}}}{\sum_{J} \alpha_{J} S_{J}}
$$

and

$$
c_{B S}^{*}=\frac{\left(\alpha_{R} S_{R}+\alpha_{K} S_{K}\right)\left[\frac{\sigma(N-1)}{2}-\frac{\left(\alpha_{R} S_{R}+\alpha_{K} S_{K}\right) \sigma(N-1)}{2\left(\alpha_{R} S_{R}+\alpha_{K} S_{K}\right)-4 S_{S} \alpha_{K}}\right]+\frac{S_{S} \alpha_{K}\left(\alpha_{R} S_{R}+\alpha_{K} S_{K}\right) \sigma(N-1)}{2(1+r)\left(\alpha_{R} S_{R}+\alpha_{K} S_{K}\right)-4 S_{S} \alpha_{K}}}{\sum_{J} \alpha_{J} S_{J}}
$$

The numerator that comprises all positive marginal utilities from a higher corruption level has two components: The first is the net marginal benefit from corruption for corrupt officials and relatives and the second is the marginal benefit from corruption for the superiors. It is easy to see that the net marginal benefit from corruption for corrupt officials and relatives is equal for both cases. Only the marginal gains for the superiors are reduced in the case with financial institutions and screening. The reason for this is the following: When choosing the entry fee, the superiors anticipate the voting behavior of corrupt officials and relatives. If the superiors would reduce the net benefits from corruption these groups by demanding a higher entry fee, this would result in a lower political support for corruption by both corrupt officials and relatives. When the relatives have the option to save at the bank, the opportunity costs of not saving at the bank reduce the surplus from corruption. By choosing a lower entry fee in the presence of financial institutions, the superior exactly compensates this loss. This way, he can achieve that the voting behavior of corrupt officials and relatives remains unchanged. That the superior exactly compensates the corrupt officials and relatives for the opportunity costs that arise in the presence of banks is the result of the linearity of the equilibrium corruption levels in $t$. However, the effect is more general: The superior always has the incentive to adjust the entry fee in order to win political allies to support high corruption levels.

For the case with financial institutions and pooling, it is interesting to look at the impact of the political responsiveness of the superiors on condition (31). First, consider the case where the superiors do not have any political influence, $S_{S}=0$. Then, we have: $c_{N}^{*}>c_{B P}^{*} \Leftrightarrow \alpha_{R} S_{R}>$ $\alpha_{K} S_{K}$ and, with the assumption that $\alpha_{K}=\alpha_{R}, S_{R}>S_{K}$. Financial institutions with pooling lead to a lower corruption level if the political responsiveness of relatives, the losers from higher corruption in the presence of banks, is higher than the responsiveness of the corrupt officials and vice versa.

For $S_{S}>0$, the expression $\left[\frac{(1+r) S_{K}^{2}+S_{S}^{2}-(2+3 r) S_{K} S_{S}}{(1+r) S_{K}^{2}+S_{S}^{2}-(2+r) S_{K} S_{S}}\right]$ is always smaller than 1 . When $S_{S}$ increases, the numerator of the right hand side of condition (31) decreases faster than the 
denominator. In the numerator, $S_{K} S_{S}$ is weighted with $(2+3 r)$, whereas in the denominator, only with $(2+r)$. Overall, an increase in $S_{S}$ makes it more likely that condition (31) is fulfilled. That is, higher political influence of the superiors increases the parameter range for which the introduction of a banking system with pooling reduces the equilibrium corruption level. The reason is that the superiors in the margin profit more form corruption in a system without banks. With banks, they internalize that the corrupt officials have to pay the interest rate $r$ to the bank. We can see this if we compare $t_{N}^{*}$ and $t_{B P}^{*}$ for the case where $\alpha_{K} S_{K}=\alpha_{R} S_{R}$. Then, we get

$$
t_{N}^{*}>t_{B P}^{*} \Leftrightarrow \frac{\alpha_{K} S_{K} \sigma(N-1)}{2 \alpha_{K} S_{K}-2 S_{S} \alpha_{K}}>\frac{\alpha_{K} S_{K} \sigma(N-1)}{2(1+r) \alpha_{K} S_{K}-2 S_{S} \alpha_{K}}
$$

As $r>0$, this inequality always holds. The reason is that they want the corrupt officials to be their allies in the support of high corruption levels. Thus, the superiors are stronger supporters of a high corruption level in the case without banks. The introduction of financial institutions reduces the superior's marginal benefits from corruption and diminishes thereby their support for high corruption levels.

Overall, our results are robust to the endogenization of the choice of the entry fee. Financial institutions with screening always decrease the equilibrium corruption level. With respect to the basic model, when banks offer pooling contracts, the introduction of the superiors as a group of voters increases the parameter range for which financial institutions reduce the corruption level.

\section{Conclusion}

The literature has studied corruption on the low levels and on the high levels of the bureaucracy separately. However, both types of corruption are linked by corruption on the intermediate levels of the bureaucracy. There, corruption occurs when superiors demand entry fees in exchange for positions on lower levels of the hierarchy. In many developing and transition countries, such second hand markets for jobs are observed. We have shown that this link between low and high level corruption and the necessity to externally finance part of the entry fee leads to the persistence of corruption if financial institutions are missing. When they finance the entry fee on the informal credit market, the corrupt officials give their relatives a stake in corruption. Therefore, their political support for anti-corruption campaigns decreases.

What are the policy implications of our model? In democratic regimes, institutions matter for the fight against corruption. Our analysis has demonstrated that financial institutions are crucial for the political success of anti-corruption policies. Therefore, substantial effort is necessary to establish a functioning financial system. Only this can create the political support that democratic governments need to implement reforms such as anti-corruption policies. Phrased differently, a politician will have incentives to run on an anti-corruption platform only with functioning financial institutions. The reason is that functioning financial institutions reduce the incentives of some groups of voters to support high levels of corruption.

Thus, for a country that strives to reduces corruption, the first step should be to establish a functioning banking system. If banks are able to screen, financial institutions always reduce 
the equilibrium corruption level. This is not too unrealistic even for developing countries: For example, corrupt officials can be excluded from getting credit if there is no consumer credit market. However, also when banks are not able to screen, the presence of a functioning banking sector provides the relatives with an additional option to invest and neutralizes their positive stake in corruption. After the establishment of financial institutions, the second step is to improve the capabilities of banks with respect to project evaluation. Moreover, banks should be given an incentive to fight against corruption by committing themselves not to finance corrupt ventures.

The mechanism we have characterized also feeds back into the incentives of a government to establish the legal and institutional environment that allows a functioning banking sector to develop. It also influences how much support a government gets for liberalizing market entry for foreign banks that commit themselves to a code of ethics including an anti-corruption policy. Therefore, the political economy of structural reforms and corruption are closely related to each other. 


\section{Appendix}

\subsection{Proof of Proposition 1}

When there are no financial institutions, both $K$ and $R$ have the same disagreement payoff: When negotiations break down, both have the option to become depositors and get $A-u(c)$. The Nash bargaining solution with symmetric bargaining power prescribes that $b^{N}$ maximize the surplus that is then split evenly among the two parties. Formally, the solution is given by:

$$
b^{N}=\arg \max \left[\left(U_{K}^{N}(c)-U_{D}^{N}(c)\right)\left(U_{R}^{N}(c)-U_{D}^{N}(c)\right)\right]
$$

This yields the following first-order condition:

$$
\frac{\partial U_{R}^{N}}{\partial b^{N}}\left(U_{K}^{N}(c)-U_{D}^{N}(c)\right)+\frac{\partial U_{K}^{N}}{\partial b^{N}}\left(U_{R}^{N}(c)-U_{D}^{N}(c)\right)=0
$$

After explicitly writing out the utility levels and simplifying, we get:

$$
\sigma(N-1) c-\left(1+b^{N}\right)(t c-A)-u(c)=A+b^{N}(t c-A)-u(c)
$$

Solving for $b^{N}$, this condition immediately yields $b^{N}=\frac{[\sigma(N-1)-t] c}{2(t c-A)}$.

\subsection{Proof of Proposition 2}

The Nash bargaining solution obtains when $b^{B S}$ maximizes the surplus that can be split among the two parties:

$$
b^{B S}=\arg \max \left[\left(U_{K}^{N B S}(c)-U_{K}^{B S}(c)\right)\left(U_{R}^{N B S}(c)-U_{R}^{B S}(c)\right)\right]
$$

Both relatives and corrupt officials have the outside option to become depositors. Therefore, the Nash bargaining solution has to fulfill:

$$
U_{K}^{N B S}(c)=U_{R}^{N B S}(c)
$$

or:

$$
\left[(N-1)+\alpha_{E} N R \gamma\right] \sigma c-\left(1+b^{B S}\right)(t c-A)-u(c)=A+b^{B S}(t c-A)+r(2 A-t c)-u(c)
$$

Solving for $b^{B S}$, this condition immediately yields $b^{B S}=\frac{[(N-1)] \sigma c-t c(1-r)-2 r A}{2(t c-A)}$.

\subsection{Proof of Proposition 3}

The Nash bargaining solution obtains when $b^{B P}$ maximizes the surplus that can be split among the two parties:

$$
b^{B P}=\arg \max \left[\left(U_{K}^{N B P}(c)-U_{K}^{B P}(c)\right)\left(U_{R}^{N B P}(c)-U_{R}^{B P}(c)\right)\right]
$$

Explicitly writing out the utility levels and simplifying yields:

$$
-\left(1+b^{B P}\right)(t c-A)+(1+r) t c=A+b^{B P}(t c-A)+r(2 A-t c) \Leftrightarrow b^{B P}=r
$$

Therefore, it is straightforward that $U_{K}^{N B P}(c)=U_{K}^{B P}(c)$ and $U_{R}^{N B P}(c)=U_{R}^{B P}(c)$. 


\subsection{Proof of Proposition 4}

The probabilistic voting model leads to a unique equilibrium if the vote shares of candidates $X$ and $Y$ are strictly concave functions of the policy platforms $c_{X}$ and $c_{Y}$. This is straightforward to show as the utilities $U_{J}(c)$ of all groups of voters are strictly concave in $c$.

By construction, the utility functions of all groups are linearly additive and comprise only terms which are linear in $c$ and the disutility from corruption $-u(c)$ (see equations 5 and 10 for the utility levels of corrupt officials and relatives after bargaining).

By definition, $-\frac{\partial^{2} u(c)}{(\partial c)}(c)<0$. This means that also the vote shares of the candidates are strictly concave in $c: \frac{\partial^{2} v}{(\partial c)^{2}}<0$. Given this, the equilibrium policy must maximize the candidates' vote share and must be existing and unique.

\subsection{Proof of Lemma 1}

To obtain the equilibrium corruption level for the situation without financial institutions, we use the utility functions defined in section 3.2 and plug them into the first order condition for the equilibrium corruption level:

$$
\frac{\partial v}{\partial c}=\sum_{J} \alpha_{J} S_{J}\left(-\frac{\partial u(c)}{\partial c}\right)+\left(\alpha_{R} S_{R}+\alpha_{K} S_{K}\right) \frac{\sigma(N-1)-t}{2}=0
$$

With $-\frac{\partial u(c)}{\partial c}<0$ and $-\frac{\partial^{2} u(c)}{(\partial c)}<0$, the equilibrium corruption level $c_{N}^{*}$ is uniquely defined.

\subsection{Proof of Lemma 2}

To obtain the equilibrium corruption level for the situation without financial institutions, we use the utility functions defined in section 3.3.1 and plug them into the first order condition for the equilibrium corruption level:

$$
\frac{\partial v}{\partial c}=0 \Leftrightarrow \sum_{J} \alpha_{J} S_{J}\left(-\frac{\partial u(c)}{\partial c}\right)+\left(\alpha_{K} S_{K}+\alpha_{R} S_{R}\right) \frac{\sigma(N-1)-(1+r) t}{2}=0
$$

With $-\frac{\partial u(c)}{\partial c}<0$ and $-\frac{\partial^{2} u(c)}{(\partial c)}<0$, the equilibrium corruption level $c_{B S}^{*}$ is uniquely defined.

\subsection{Proof of Lemma 3}

To obtain the equilibrium corruption level for the situation with financial institutions and pooling, we use the utility functions defined in section 3.3.2 and plug them into the first order condition for the equilibrium corruption level:

$$
\frac{\partial v}{\partial c}=0 \Leftrightarrow \sum_{J} \alpha_{J} S_{J}\left(-\frac{\partial u(c)}{\partial c}\right)+\alpha_{K} S_{K}[\sigma(N-1)-(1+r) t]=0
$$

With $-\frac{\partial u(c)}{\partial c}<0$ and $-\frac{\partial^{2} u(c)}{(\partial c)}<0$, the equilibrium corruption level $c_{B P}^{*}$ is uniquely defined. 


\subsection{Proof of Proposition 5}

Comparing the first order conditions for the equilibrium corruption levels in the case without a bank (as derived in lemma 1) and with banks offering screening contracts (as derived in lemma 2) yields:

$$
\frac{\partial u\left(c_{N}^{*}\right)}{\partial c}-\frac{\partial u\left(c_{B S}^{*}\right)}{\partial c}=\frac{\left(\alpha_{K} S_{K}+\alpha_{R} S_{R}\right) \frac{\sigma(N-1)-t}{2}}{\sum_{J} \alpha_{J} S_{J}}-\frac{\left(\alpha_{K} S_{K}+\alpha_{R} S_{R}\right) \frac{\sigma(N-1)-(1+r) t}{2}}{\sum_{J} \alpha_{J} S_{J}}
$$

This difference is positive if and only if $\frac{-r t\left(\alpha_{K} S_{K}+\alpha_{R} S_{R}\right)}{2}<0$. This is always true. As $u(c)$ is strictly convex in $c$ and thus $-\frac{\partial u(c)}{\partial c}<0$ and $-\frac{\partial^{2} u(c)}{(\partial c)}<0$, this means that $c_{N}^{*}>c_{B S}^{*}$.

\subsection{Proof of Proposition 6}

Comparing the first order conditions for the equilibrium corruption levels in the case without a bank (as described in lemma 1) and with banks offering pooling contracts (as described in lemma 3) yields:

$$
\frac{\partial u\left(c_{N}^{*}\right)}{\partial c}-\frac{\partial u\left(c_{B P}^{*}\right)}{\partial c}=\frac{\left(\alpha_{K} S_{K}+\alpha_{R} S_{R}\right) \frac{\sigma(N-1)-t}{2}}{\sum_{J} \alpha_{J} S_{J}}-\frac{\alpha_{K} S_{K}(\sigma(N-1)-(1+r) t)}{\sum_{J} \alpha_{J} S_{J}} .
$$

This difference is positive if and only if $\alpha_{K} S_{K}\left(\frac{\sigma(N-1)-t}{2}-r t\right)<\alpha_{R} S_{R} \frac{\sigma(N-1)-t}{2}$.

When this condition is fulfilled, as $u(c)$ is strictly convex in $c$ and thus $-\frac{\partial u(c)}{\partial c}<0$ and $-\frac{\partial^{2} u(c)}{(\partial c)}<0$, this means that $c_{N}^{*}>c_{B P}^{*}$.

\subsection{Proof of Lemma 4}

To obtain the equilibrium corruption level for the situation without financial institutions, we use the utility functions defined in sections $3.2,3.3 .1$, and 3.3 .2 , substituting $-\frac{1}{2} c^{2}$ for $-u(c)$. In addition, we take the utility function of the superiors from equation (23), weighted with the political influence and group size of the superiors $\alpha_{S} S_{S}$. We plug that into the first order condition for the equilibrium corruption level as defined in proposition 4 .

For the case without financial institutions, the first order condition then reads:

$$
-c \sum_{J} \alpha_{J} S_{J}+\left(\alpha_{R} S_{R}+\alpha_{K} S_{K}\right)\left(\frac{\sigma(N-1)-t}{2}\right)+S_{S} \alpha_{K} t=0
$$

Solving for $c$, we obtain the equilibrium corruption level $c_{N}^{*}(t)$.

For the case with financial institutions with screening, we get:

$$
-c \sum_{J} \alpha_{J} S_{J}+\left(\alpha_{R} S_{R}+\alpha_{K} S_{K}\right)\left(\frac{\sigma(N-1)-(1+r) t}{2}\right)+S_{S} \alpha_{K} t=0
$$

Solving for $c$, we obtain the equilibrium corruption level $c_{B S}^{*}(t)$.

For the case with financial institutions with pooling, we get:

$$
-c \sum_{J} \alpha_{J} S_{J}+\alpha_{K} S_{K}(\sigma(N-1)-(1+r) t)+S_{S} \alpha_{K} t=0
$$

Solving for $c$, we obtain the equilibrium corruption level $c_{B P}^{*}(t)$. 


\subsection{Proof of Lemma 5}

For the case without financial institutions: Plugging $c_{N}^{*}(t)$ in the first order condition of the superiors' maximization problem yields:

$$
\left(\alpha_{R} S_{R}+\alpha_{K} S_{K}\right) \frac{\sigma(N-1)-t}{2}+S_{S} \alpha_{K} t=\frac{1}{2}\left(\alpha_{R} S_{R}+\alpha_{K} S_{K}\right) t-S_{S} \alpha_{K} t
$$

Or, solving for $t_{N}^{*}$ :

$$
t_{N}^{*}=\frac{\left(\alpha_{R} S_{R}+\alpha_{K} S_{K}\right) \sigma(N-1)}{2\left(\alpha_{R} S_{R}+\alpha_{K} S_{K}\right)-4 S_{S} \alpha_{K}}
$$

For the case with financial institutions and screening: Plugging $c_{B S}^{*}(t)$ in the first order condition of the superiors' maximization problem yields:

$$
\left(\alpha_{R} S_{R}+\alpha_{K} S_{K}\right) \frac{\sigma(N-1)-(1+r) t}{2}+S_{S} \alpha_{K} t=\frac{(1+r)\left(\alpha_{R} S_{R}+\alpha_{K} S_{K}\right)}{2} t-S_{S} \alpha_{K} t
$$

Or, solving for $t_{B S}^{*}$ :

$$
t_{B S}^{*}=\frac{\left(\alpha_{R} S_{R}+\alpha_{K} S_{K}\right) \sigma(N-1)}{2(1+r)\left(\alpha_{R} S_{R}+\alpha_{K} S_{K}\right)-4 S_{S} \alpha_{K}}
$$

For the case with financial institutions and pooling: Plugging $c_{B P}^{*}(t)$ in the first order condition of the superiors' maximization problem yields:

$$
\alpha_{K} S_{K}(\sigma(N-1)-(1+r) t)+S_{S} \alpha_{K} t=\alpha_{K} S_{K}(1+r) t-S_{S} \alpha_{K} t
$$

Or, solving for $t_{B P}^{*}$

$$
t_{B P}^{*}=\frac{\alpha_{K} S_{K} \sigma(N-1)}{2(1+r) \alpha_{K} S_{K}-4 S_{S} \alpha_{K}}
$$

\subsection{Proof of Proposition 7}

The equilibrium corruption level without financial institutions $c_{N}^{*}$ is:

$$
\begin{aligned}
c_{N}^{*}= & \frac{1}{\sum_{J} \alpha_{J} S_{J}}\left[\left(\alpha_{R} S_{R}+\alpha_{K} S_{K}\right)\left(\frac{\sigma(N-1)}{2}-\frac{\left(\alpha_{R} S_{R}+\alpha_{K} S_{K}\right) \sigma(N-1)}{2\left(\alpha_{R} S_{R}+\alpha_{K} S_{K}\right)-4 S_{S} \alpha_{K}}\right)\right. \\
& \left.+S_{S} \alpha_{K} \frac{\left(\alpha_{R} S_{R}+\alpha_{K} S_{K}\right) \sigma(N-1)}{2\left(\alpha_{R} S_{R}+\alpha_{K} S_{K}\right)-4 S_{S} \alpha_{K}}\right]
\end{aligned}
$$

For the case where banks have access to a perfect screening technology, the equilibrium corruption level $c_{B S}^{*}$ is:

$$
\begin{aligned}
c_{B S}^{*}= & \frac{1}{\sum_{J} \alpha_{J} S_{J}}\left[\left(\alpha_{R} S_{R}+\alpha_{K} S_{K}\right)\left(\frac{\sigma(N-1)}{2}-\frac{\left(\alpha_{R} S_{R}+\alpha_{K} S_{K}\right) \sigma(N-1)}{2\left(\alpha_{R} S_{R}+\alpha_{K} S_{K}\right)-4 S_{S} \alpha_{K}}\right)\right. \\
& \left.+S_{S} \alpha_{K} \frac{\left(\alpha_{R} S_{R}+\alpha_{K} S_{K}\right) \sigma(N-1)}{2(1+r)\left(\alpha_{R} S_{R}+\alpha_{K} S_{K}\right)-4 S_{S} \alpha_{K}}\right]
\end{aligned}
$$

We can compare the equilibrium corruption levels for the case without financial institutions and the case with financial institutions with screening and get that $c_{N}^{*}>c_{B S}^{*}$ if and only if:

$$
S_{S} \alpha_{K} \frac{\left(\alpha_{R} S_{R}+\alpha_{K} S_{K}\right) \sigma(N-1)}{2\left(\alpha_{R} S_{R}+\alpha_{K} S_{K}\right)-4 S_{S} \alpha_{K}}>S_{S} \alpha_{K} \frac{\left(\alpha_{R} S_{R}+\alpha_{K} S_{K}\right) \sigma(N-1)}{2(1+r)\left(\alpha_{R} S_{R}+\alpha_{K} S_{K}\right)-4 S_{S} \alpha_{K}}
$$


or:

$$
2(1+r)\left(\alpha_{R} S_{R}+\alpha_{K} S_{K}\right)-4 S_{S} \alpha_{K}>2\left(\alpha_{R} S_{R}+\alpha_{K} S_{K}\right)-4 S_{S} \alpha_{K}
$$

This reduces to $(1+r)>1$. As $r>0$, this is always true.

For the case where banks can only offer pooling contracts, the equilibrium corruption level $c_{B P}^{*}$ is:

$$
\begin{aligned}
c_{B P}^{*}= & \frac{1}{\sum_{J} \alpha_{J} S_{J}}\left[\alpha _ { K } S _ { K } \left(\sigma(N-1)-\frac{\alpha_{K} S_{K} \sigma(N-1)}{2(1+r) \alpha_{K} S_{K}-2 S_{S} \alpha_{K}}\right.\right. \\
& \left.+S_{S} \alpha_{K} \frac{\alpha_{K} S_{K} \sigma(N-1)}{2(1+r) \alpha_{K} S_{K}-2 S_{S} \alpha_{K}}\right]
\end{aligned}
$$

We can compare the equilibrium corruption levels for the case without financial institutions and the case with financial institutions and pooling and get that $c_{N}^{*}>c_{B P}^{*}$ if and only if:

$$
\begin{aligned}
& \alpha_{R} S_{R}-\frac{\left(\alpha_{R} S_{R}+\alpha_{K} S_{K}\right)^{2}-2 S_{S} \alpha_{K}\left(\alpha_{R} S_{R}+\alpha_{K} S_{K}\right)}{2\left(\alpha_{R} S_{R}+\alpha_{K} S_{K}\right)-4 S_{S} \alpha_{K}} \\
> & \alpha_{K} S_{K}-\frac{\alpha_{K} S_{K}}{\alpha_{K} S_{K}-S_{S} \alpha_{K}}+\frac{S_{S} \alpha_{K} \alpha_{K} S_{K}}{(1+r) \alpha_{K} S_{K}-S_{S} \alpha_{K}}
\end{aligned}
$$

Further simplification yields:

$$
\alpha_{R} S_{R}>\alpha_{K} S_{K}\left[3-\frac{2 \alpha_{K} S_{K}}{\alpha_{K} S_{K}-S_{S} \alpha_{K}}+\frac{2 S_{S} \alpha_{K}}{(1+r) \alpha_{K} S_{K}-S_{S} \alpha_{K}}\right]
$$

and finally:

$$
\alpha_{R} S_{R}>\alpha_{K} S_{K}\left[\frac{(1+r) S_{K}^{2}+S_{S}^{2}-(2+3 r) S_{K} S_{S}}{(1+r) S_{K}^{2}+S_{S}^{2}-(2+r) S_{K} S_{S}}\right]
$$




\section{References}

[1] Abed, George T. and Hamid R. Davoodi (2000): Corruption, Structural Reform, and Economic Performance in the Transition Economies, IMF Working Paper WP/00/132, Washington DC, IMF

[2] Acemoglu, Daron and Thierry Verdier (2000): The Choice between Market Failure and Corruption, American Economic Review 90(1), 194-211

[3] Acemoglu, Daron and Thierry Verdier (1998): Property Rights, Corruption and the Allocation of Talent: A General Equilibrium Approach, Economic Journal 108, 1381-1403

[4] Aidt, Toke S. (2003): Economic Analysis of Corruption: A Survey, Economic Journal 113, F632 - F658

[5] Bardhan, Pranhab (1997): Corruption and Development: A Review of Issues, Journal of Economic Literature 35, 1320-1346

[6] Beck, Paul B. and Michael W. Maher (1986): A Comparison of Bribery and Bidding in Thin Markets, Economic Letters 20, 1-5

[7] Besley, Timothy and John McLaren (1993): Taxes and Bribery: The Role of Wage Incentives, Economic Journal 103, 119-41

[8] Brunetti, Aymo and Beatrice Weder (2003): A Free Press is Bad News for Corruption. Journal of Public Economics 87, 1801-1824

[9] Coate, Stephen and Stephen Morris (1995): On the Form of Transfers to Special Interests, Journal of Political Economy 103, 1210-1235

[10] Coughlin, Peter and Shmuel Nitzan (1981): Directional and Local Electoral Equilibria with Probabilistic Voting, Journal of Economic Theory 24, 226-239

[11] Dixit, Avinash and Peter Londregan (1996): The Determinants of Sucess of Special Interests in Redistributive Politics, The Journal of Politics 58, 4: 1132-1155

[12] Djankov, Simeon, Rafael La Porta, Florencio Lopez-de-Silanes, Andrei Shleifer (2002): The Regulation of Entry, Quarterly Journal of Economics 117,1: 1-37

[13] EBRD (2002), Transition Report 2002: Agriculture and Rural Transition, EBRD: London.

[14] Foellmi, Reto and Manuel Oechslin (2003): Who Gains from Non-Collusive Corruption?, University of Zurich Working Paper No. 142

[15] Grossman, Gene M. and Elhanan Helpman (2001): Special Interest Polititcs, Cambridge, Mass.: MIT Press

[16] Hillman, Ayre L. and Eliakim Katz (1987): Hierarchical Structure and the Social Costs of Bribes and Transfers, Journal of Public Economics 34, 129-142

[17] Jain, Arvind K. (2001a): Corruption: A Review, Journal of Economic Surveys 15, 1: 71-121

[18] Jain, Arvind K. (2001b): The Political Economy of Corruption, London: Routhledge

[19] Jain, Arvind K. (1998): Economics of Corruption, Boston: Kluwer Academic Publishers

[20] Knack, Stephen and Philip Keefer (1996): Institutions and Economic Performance: CrossCountry Tests Using Alternative Institutional Measures, Economics and Politics 7, 3: 207-27 
[21] Laffont, Jean-Jacques and Tchétché N'Guessan (1999): Competition and Corruption in an Agency Relationship, Journal of Development Economics 60: 271-95

[22] La Porta, Rafael, Florencio Lopez-de-Silanes, Andrei Shleifer and Robert W. Vishny (2000): Investor Protection and Corporate Governance, Journal of Financial Economics, 58, 1-2: $3-27$

[23] La Porta, Rafael, Florencio Lopez-de-Silanes, Andrei Shleifer and Robert W. Vishny (1998): Law and Finance, Journal of Political Economy, 106,6: 1113-1155

[24] La Porta, Rafael, Florencio Lopez-de-Silanes, Andrei Shleifer and Robert W. Vishny (1997): Legal Determinants of External Finance, Journal of Finance, 52,3: 1131-1150

[25] Lindbeck, Assar and Jorgen W. Weibull (1987): Balanced-Budget Redistribution as the Outcome of Political Competition, Public Choice 52, 273-297

[26] Lui, Francis T. (1985): An Equilibrium Queuing Model of Bribery, Journal of Political Economy 93, 4: 760-81

[27] Mauro, Paolo (1995): Corruption and Growth, Quarterly Journal of Economics 110, 681712

[28] Mookherjee, Dilip and Ivan P.L. Png (1995): Corruptible Law Enforcers: How Should They Be Compensated?, Economic Journal 105, 145-59

[29] Persson, Torsten, Guido Tabellini, and Francesco Trebbi (2003): Electoral Rules and Corruption, Journal of the European Economic Association, 1,4: 958-989

[30] Persson, Torsten and Guido Tabellini (2000): Political Economics: Explaining Economic Policy, Cambridge, Mass. MIT Press Economic Review 43: 699-753

[31] Persson, Torsten, Gérard Roland and Guido Tabellini (1997): Separation of Powers and Political Accountability, Quarterly Journal of Economics 112,4: 1163-1202

[32] Rose-Ackerman, Susan (1999): Corruption and Government: Causes, Consequences, and Reform, Cambridge: Cambridge University Press

[33] Rose-Ackerman, Susan (1975): The Economics of Corruption, Journal of Public Economics 4, 187-203

[34] Shleifer, Andrei and Robert Vishny (1998): The Grabbing Hand, Government Pathologies and Their Cures, Cambridge, MA: Harvard University Press

[35] Shleifer, Andrei and Robert Vishny (1993): Corruption, Quarterly Journal of Economics $108,599-618$

[36] Treisman, Daniel (2000): The Causes of Corruption: A Cross-national Study, Journal of Public Economics 76, 399-457

[37] Wade, Robert (1982): The System of Administrative and Political Corruption: Canal Irrigation in South India, Journal of Development Studies 18, 3: 287-328

[38] Worldbank (1998): New Frontiers in Diagnosing and Combating Corruption, PREM notes No. 7, October 1998, Washington DC, Worldbank 